\title{
El emplazamiento de producto: conceptualización, nuevos formatos y efectos sobre el consumidor
}

\section{Hhan}

Resumen

\author{
José Martí Parreño \\ Joaquín Aldás Manzano \\ Rafael Currás Pérez \\ Isabel Sánchez García \\ Universitat de València \\ Departamento de Comercialización e \\ Investigación de Mercados
}

El emplazamiento de producto es una herramienta de las comunicaciones de marketing que ha experimentado un continuo crecimiento en los últimos años. El aumento de su uso ha supuesto también la aparición de nuevos formatos y contextos con el fin de incrementar su eficacia. Así, en los últimos años han aparecido diversas evoluciones del emplazamiento de producto tradicional, como las marcas enmascaradas, el emplazamiento de producto inverso o las marcas mejoradas. El objetivo central de este artículo es realizar una aproximación teórica a estos nuevos formatos de emplazamiento de producto, señalando su naturaleza y principales características. Además, se examinan los diferentes efectos cognitivos, afectivos y comportamentales que pueden alcanzarse mediante el empleo de estas herramientas de las comunicaciones de marketing. En las conclusiones se plantean algunas consideraciones éticas y morales que implica el uso de estos formatos, y se apuntan las líneas de investigación más importantes que se derivan de ellos.

Palabras | Emplazamiento de producto, emplazamiento de producto

CLAVE inverso, marcas enmascaradas, marcas mejoradas, comportamiento del consumidor

Correos electrónicos: marpajo@alumni.uv.es•joaquin.aldas@uv.es

-rafael.curras-perez@uv.es•isabel.sanchez@uv.es 
El emplazamiento de producto:

conceptualización, nuevos formatos

y efectos sobre el consumidor

\section{Introducción}

En la actualidad, el nuevo contexto competitivo provoca que las comunicaciones de marketing sean vistas desde una óptica de comunicación de marketing integral (Schultz, 1996). Este enfoque implica el uso de un abanico más amplio de herramientas de comunicación que las tradicionales (publicidad, relaciones públicas, promoción de ventas y venta personal) a la par que permite ampliar los objetivos a alcanzar por estas comunicaciones (Fill, 2006). Esto explica que las empresas estén reorientando los presupuestos destinados a comunicaciones de marketing hacia los denominados medios alternativos (entre los que se incluyen, entre otros, el marketing de eventos, el advergaming' o el emplazamiento de producto).Varios factores adicionales permiten justificar esta migración hacia medios alternativos, por ejemplo la creciente saturación publicitaria, la fragmentación (incluso la microfragmentación en el caso de la web) del panorama mediático actual o los usos cada vez más complejos de los diversos medios de comunicación que los consumidores tienen a su alcance.

Dentro de estos medios alternativos, el emplazamiento de producto es una herramienta de las comunicaciones de marketing en plena expansión. Este hecho de evidencia tanto por la importancia cada vez mayor de esta herramienta en los presupuestos de marketing de las organizaciones (PQ Media, 2008), como por un creciente interés académico que ha conducido a un incremento del número de trabajos relacionados con el emplazamiento de producto en los últimos años. ${ }^{2}$ Este aumento del uso de la herramienta por parte de las organizaciones, ha supuesto también la aparición de nuevos formatos y contextos con el fin de incrementar su eficacia.Así, en los últimos años han aparecido diversas evoluciones del emplazamiento de producto tradicional, como las marcas enmascaradas, el emplazamiento de producto inverso o las marcas mejoradas, que tienen rasgos y aplicaciones específicos, y que sin embargo han recibido escasa atención desde un punto de vista académico (Gutnik, et al,2007).

De tal suerte, el objetivo fundamentalal de este artículo es realizar una aproximación teórica a los principales formatos de emplazamiento de producto que, partiendo del marco del emplazamiento tradicional, ofrecen nuevas

' El advergaming ha sido definido como "la creación de videojuegos orientados a las comunicaciones de marketing" (Martí, 2010: 78).

${ }^{2}$ Véase una revisión en Balasubramanian, Karrh y Patwardhan (2006). 
posibilidades a las comunicaciones de marketing de las organizaciones. Para ello, en el primer apartado se aborda la delimitación conceptual del emplazamiento de producto en el contexto de los mensajes híbridos utilizados en las comunicaciones de marketing (Balasubramanian, 1994). En el segundo apartado se analizan los nuevos formatos (marcas enmascaradas, emplazamiento de producto inverso y marcas mejoradas) que han ido surgiendo a partir del emplazamiento de producto clásico, señalando su naturaleza y principales características. En el siguiente apartado se examinan los diferentes efectos cognitivos, afectivos y comportamentales que pueden alcanzarse mediante el uso de estas herramientas de las comunicaciones de marketing. Por último, en las conclusiones se plantean varias consideraciones éticas y morales que conllevan algunos de estos formatos (en especial cuando se dirigen a audiencias sensibles, como niños y adolescentes), y se apuntan las principales líneas de investigación que podrían requerir estos nuevos formatos.

\section{Conceptualización del emplazamiento de producto}

\section{Orígenes del emplazamiento de producto}

Los orígenes del emplazamiento de producto se remontan al nacimiento de los medios de comunicación de masas. De hecho, el desarrollo de la radionovela como género de entretenimiento se debe al interés de los anunciantes por emplazar sus productos en programas de entretenimiento que llegaran a una audiencia millonaria y bien segmentada (López-Pumarejo, 1987; Lavin, 1995). Las principales marcas de jabones, detergentes y otros productos para el hogar empiezan a basar su estrategia publicitaria en la creación de radionovelas en las que se emplazan verbalmente sus productos de forma destacada: "Entre el 1933 y el 1937 la radionovela se convirtió en la programación diurna por excelencia. Compañías del tipo de Procter \& Gamble, la American Home Products, la Pillsburry y la General Foods habían asumido definitivamente al soap como su principal recurso publicitario" (López-Pumarejo, 1987: 139).

En otros medios como el cinematográfico, el uso de esta herramienta se remonta, al menos, a los años veinte (Galician y Bourdeau, 2004), si bien Nebenzahl y Secunda (1993) aseguran que la primera vez que se puede constatar que un emplazamiento se produce a cambio de una compensación económica es en 1945, cuando Joan Crawford bebe Jack Daniel's delante de la cámara 
El emplazamiento de producto:

conceptualización, nuevos formatos

y efectos sobre el consumidor

en la película Alma en suplicio (Curtiz, 1945). Sin embargo, los inicios de una auténtica industria del emplazamiento de producto en el cine de Hollywood no llegaría hasta casi cuatro décadas después con el estreno de E.T el extraterrestre (Spielberg, 1982). La marca Hershey's logró emplazar, con un marcado protagonismo argumental, sus caramelos de brillantes colores Reese's pieces en varias secuencias de la película. Los caramelos se publicitaron como "los caramelos de E.T.", y el importante incremento de 65 por ciento de las ventas en los meses posteriores al estreno de la película (Karrh, 1994) supuso que otros anunciantes dirigieran definitivamente su atención hacia el emplazamiento de producto.

En la actualidad el uso del emplazamiento de producto está adquiriendo una creciente importancia dentro del conjunto de herramientas de las comunicaciones de marketing, como lo demuestra el hecho de que el número de marcas emplazadas en producciones cinematográficas ha ido en aumento (Panda,2004). Así, en el largometraje Sexo en Nueva York (King, 2008) se han llegado a detectar 94 marcas emplazadas. Parece evidente que el continuo encarecimiento de los costes de producción anima a las productoras a buscar nuevas fuentes de financiación para sus producciones, por ejemplo a través de acuerdos mediante el emplazamiento de producto. También en el medio televisivo se observa una creciente presencia de marcas emplazadas tanto en series de ficción como en realities ${ }^{3}$ (Balasubramanian, Karrh y Patwardhan, 2006; Consoli, 2004). En el caso de American Idol, Coca-Cola aparece de forma prominente no sólo como bebida "oficial" del jurado (con vasos de Coca-Cola emplazados siempre bien visibles en su mesa), sino a través de estancias como "la habitación roja" (decorada con el color corporativo de la marca y con máquinas expendedoras de su bebida instaladas en ella).

La pérdida de eficacia de otras herramientas tradicionales de las comunicaciones de marketing (Elliot, 1992; Meenaghan, 1991), como el spot televisivo, está obligando a los anunciantes a buscar nuevas herramientas que sustituyan

${ }^{3}$ Se entiende por realities, reality shows o programas de telerrealidad, aquellos programas televisivos que son protagonizados por personas reales (anónimas o famosas) en contraposición al concepto de programación de ficción protagonizada por actores. Estos realities (generalmente concursos tipo Gran Hermano o Supervivientes) muestran el comportamiento de estas personas en un determinado entorno en el que se encuentran cautivas (por ejemplo un plató de televisión o una isla).

Teoría y Praxis

8 (2010: II3-136) 
o complementen sus antiguas estrategias de comunicación. En este sentido, puesto que el emplazamiento de producto forma parte del contenido de entretenimiento (está integrado en una película o un videojuego) es capaz de evitar comportamientos del consumidor que perjudiquen la eficacia del mensaje publicitario, como el zapping ${ }^{4}$ o el zipping 5 . Por ello, resulta evidente que el emplazamiento de producto está ganando terreno en los presupuestos de marketing de las organizaciones en los últimos años como demuestra el continuo incremento de la inversión mundial en emplazamiento de producto. En 2008 este incremento fue de 19 por ciento, alcanzando una inversión de 3.460 millones de dólares en Estados Unidos y una estimación de crecimiento de 14 por ciento para 2009 (Vranica, 2009).

\section{El emplazamiento de producto como "mensaje híbrido"}

El emplazamiento de producto ha sido descrito como "la práctica de incluir el nombre, producto, embalaje, señalización u otro artículo de merchandising ${ }^{6}$ de una marca, en una película de cine, en televisión o en otros medios con el fin de incrementar la notoriedad y el reconocimiento inmediato de la marca en el punto de compra" (Panda, 2004: 42). Esta herramienta de las comunicaciones de marketing se enmarca en los denominados mensajes híbridos, definidos como "todo intento pagado de influir a las audiencias para obtener un beneficio comercial usando comunicaciones que presentan un carácter no comercial; bajo estas circunstancias, las audiencias pueden no ser conscientes del intento de influencia comercial y/o de procesar el contenido de estas comunicaciones de forma diferente a como procesan los mensajes comerciales" (Balasubramanian, 1994:29). Es decir, los mensajes híbridos gozan de las ventajas de dos de las principales herramientas de comunicación no personal utilizadas tradicionalmente por las organizaciones: la publicidad y la publicidad gratuita. Por una parte, estos mensajes son pagados por la organización, lo que permite un control sobre los ellos (publicidad); por otra, la organización no es identificada claramente

\footnotetext{
${ }^{4}$ Se entiende por zapping o zapeo el "cambio reiterado de canal de televisión por medio del mando a distancia” (Real Academia Española, 200I: 2340).

${ }^{5}$ Se denomina zipping al avance rápido de la programación televisiva que ha grabado previamente el telespectador.

${ }^{6}$ En este caso se entiende por merchandising los objetos promocionales utilizados en una campaña de comunicación de una organización.
} 
como emisora del mensaje, por lo que su aparente falta de intención comercial (publicidad gratuita) puede redundar en una mayor credibilidad del mensaje por parte del receptor (Balasubramanian, 1994).

No obstante, la presencia de una marca en una película, o en cualquier otro género de entretenimiento, no debe considerarse siempre emplazamiento de producto. Para que esta presencia sea calificada técnicamente como emplazamiento de producto es necesario que tal emplazamiento conlleve algún tipo de compensación (económica o de otro tipo) por parte de la organización para la que se produce el emplazamiento. Esta clase de retribución no tiene que hacerse obligatoriamente mediante una compensación económica directa, sino que puede realizarse a través de diferentes acuerdos (Karrh, 1998; Avery y Ferraro, 2000). Así, en el caso del cine, es habitual que la marca emplazada facilite para el rodaje material que resulta especialmente costoso (como coches u otros vehículos); que proporcione servicios de catering ${ }^{7}$ (en el caso de marcas de refrescos y alimentación); o que efectúe campañas publicitarias promocionales de la película. Por ejemplo Ford, debido a los acuerdos alcanzados para el emplazamiento de su nuevo modelo de Aston Martin en la película de James Bond Muere otro día (Tamahori, 2002), invirtió 17 millones de dólares en la promoción de la película. También BMW primó el emplazamiento de su nuevo modelo Z3 Roadster en la película Goldeneye (Campbell, 1995) mediante promociones en los concesionarios, eventos especiales y anuncios antes y después del estreno de la película (Balasubramanian, Karrh y Patwardhan, 2006).

Una vez acordadas las condiciones del emplazamiento, la marca puede ser emplazada tanto verbal (script placements) como visualmente (screen placements). Los emplazamientos visuales operan según un rango de proximidad de manera que los emplazamientos en escena (on-set placements) se encuentran cercanos o incluso interactúan con los protagonistas, mientras que los emplazamientos creativos (creative placements) se sitúan en lugares periféricos (por ejemplo, vallas publicitarias en edificios) más alejados del centro de la escena. Un tercer modo de emplazamiento (plot placements) permite integrar los emplazamientos (ya sean script placements o screen placements) en el hilo narrativo-argumental

${ }^{7}$ Catering es el "servicio de suministro de comidas y bebidas a aviones, trenes, colegios, etc." (Real Academia Española, 200I: 48I). 
a lo largo de toda la película (Russell, 1999). En el cuadro I se ofrecen algunos ejemplos cinematográficos de estos tipos de emplazamiento.

CuAdro I. Diferentes ejeMplos de emplazamiento en Películas

\begin{tabular}{llll|}
\hline $\begin{array}{c}\text { Tipo de } \\
\text { emplazamiento }\end{array}$ & \multicolumn{1}{c}{ Película } & \multicolumn{1}{c}{ Procedimiento } & Marca \\
\hline Verbal & Austin Powers 2 & $\begin{array}{l}\text { El protagonista dice: } \\
\text { "Hey! Hey! Hey! Quita } \\
\text { tus manos de mi Hiney, } \\
\text { nena" }\end{array}$ & Heineken \\
\hline Visual (on-set) & $\begin{array}{l}\text { El secreto de Thomas } \\
\text { Crown }\end{array}$ & $\begin{array}{l}\text { La coprotagonista, } \\
\text { René Russo, se bebe en } \\
\text { dos largos tragos una } \\
\text { lata de Pepsi One }\end{array}$ & Pepsi One \\
\hline Visual (creativo) & FX Efectos mortales 2 & $\begin{array}{l}\text { Hay un cartel luminoso } \\
\text { de Budweiser en casa } \\
\text { de uno de los protago- } \\
\text { nistas }\end{array}$ & Budweiser \\
\hline Argumental & Tin Cup & $\begin{array}{l}\text { Kevin Costner utiliza } \\
\text { durante toda la película } \\
\text { material de golf de } \\
\text { Taylor Made }\end{array}$ & Taylor \\
\hline
\end{tabular}

Fuente: Elaboración propia.

\section{Nuevos formatos de emplazamiento de producto}

El incremento en el uso del emplazamiento de producto como herramienta de las comunicaciones de marketing ha llevado a los anunciantes a experimentar con nuevos formatos de emplazamiento y a diseñar nuevas estrategias que permitan expandir los objetivos de sus acciones mediante este instrumento. La colonización de nuevos espacios en los que emplazar marcas y productos (por ejemplo, el cine de animación dirigido al público infantil) o la posibilidad de mejorar la imagen de marca a través de un emplazamiento se ha traducido en 
El emplazamiento de producto:

conceptualización, nuevos formatos

y efectos sobre el consumidor

la aparición de una serie de mutaciones del emplazamiento tradicional, que van desde el emplazamiento de marcas enmascaradas al de marcas mejoradas, como analizaremos en los siguientes apartados.

\section{Marcas enmascaradas}

La presencia de marcas enmascaradas es especialmente perceptible en las películas de animación dirigidas al público infantil, las cuales supone un fenómeno creciente capaz de alcanzar audiencias internacionales millonarias. Películas como La era de hielo 3 (Saldanha y Thurmeier, 2009), Shrek 2 (Adamson,Asbury y Vernon, 2004) o Buscando a Nemo (Stanton y Unkrich, 2003) figuran respectivamente en los puestos 14,16 y 18 dentro de las 100 más taquilleras de toda la historia (IMDB, 2010). Estas cintas son vistas por millones de espectadores de todo el mundo, lo que las convierte, para un gran número de organizaciones, en un medio atractivo a través del cual difundir sus comunicaciones de marketing.Además, su largo ciclo de vida (no sólo su periodo de exhibición en salas cinematográficas sino también su posterior difusión televisiva y su comercialización en DVD) permite exponer durante mucho tiempo estas comunicaciones a los públicos objetivo a los que van enfocadas. Entre estos públicos objetivo no sólo se encuentra el infantil, sino también adultos (por ejemplo, padres) que suelen acompañar a los niños al cine o que posteriormente ven el DVD de la película en casa.

Sin embargo, el emplazamiento de producto en este tipo de cintas de animación puede encontrarse con dificultades ya que, en muchas ocasiones, el argumento de la película se desarrolla en entornos fantásticos o irreales en los que el emplazamiento de una marca real aparece totalmente fuera de contexto. La necesidad de emplazar de forma congruente marcas reales en los mundos de fantasía presentados por este tipo de animaciones ha dado como resultado el surgimiento de un nuevo formato de emplazamiento de producto mediante las denominadas marcas enmascaradas, que han sido calificadas como "el disfraz de una marca en un baile de máscaras" (Vedrashko, 2006: 57). Así, Coca-Cola se disfraza de Coral-Cola para aparecer en el fantasioso arrecife submarino en el que se desarrolla El espantatiburones (Bergeron, Jenson y Letterman, 2004), mientras que Old Navy y Burguer King lo hacen de Old Wavy y Burguer Fish respectivamente en la misma película. Este formato supone un fenómeno creciente utilizado cada vez por más marcas, como Starbucks o Versace, que se 
presentan enmascaradamente como Farbucks y Versarchery en Shrek 2 (Adamson, Asbury y Vernon, 2004).

En nuestra opinión, una marca enmascarada puede ser identificada como tal cuando: a) se produce una asociación inmediata por parte del espectador entre esta marca y la real, y b) esta asociación ha sido planificada con objetivos de marketing (es decir, no es fruto de una parodia inocente). De tal modo, las marcas enmascaradas podrían ser definidas como marcas ficticias cuyos elementos de diseño (elementos gráficos, tipográficos, etc.) y de uso (correspondiente a la categoría de producto de la marca real) permiten una asociación inmediata entre la marca ficticia y la real. Las marcas enmascaradas, a diferencia de otras marcas ficticias, son emplazadas con objetivos de marketing. Las marcas ficticias han sido utilizadas frecuentemente en el cine, por ejemplo, cuando el propietario de una marca no ha permitido su emplazamiento en una película. El director, entonces, ha recurrido a la creación de una marca ficticia que, representando la categoría del producto requerido, desempeña su función en la cinta. En otras ocasiones, el propio director puede, de forma intencionada, inventar sus propias marcas ficticias con fines creativos o irónicos. Como el director cinematográfico Quentin Tarantino, quien tiene una larga tradición en la creación de marcas ficticias de marcado tono sarcástico con las que ha ido poblando sus películas (por ejemplo, la marca de cigarrillos Red Apple, la cadena de restaurantes Jack Rabbit Slim's Restaurants o el Big Kahuna Burger).

La ventaja más relevante de este formato de emplazamiento de producto es que se dota a la marca de un disfraz cargado de significado en el contexto de la película. El hecho de que su enmascaramiento se produzca habitualmente mediante una parodia o guiño a un espectador que debe actualizar su significado (por ejemplo, la marca Old Navy aparece enmascarada como Old Knavery en el cuento de hadas en el que se desarrolla Shrek 2 [Adamson,Asbury y Vernon, 2004 puede además minimizar la percepción por parte del espectador del objetivo real de la presencia de la marca enmascarada en la película (considerándola más una cita intertextual que un emplazamiento con intencionalidad persuasiva).

Las cintas de animación dirigidas al público infantil no son el único género cinematográfico en el que se pueden utilizar convenientemente las marcas enmascaradas. En El príncipe de Zamunda (Landis, 1988), McDonald's realizó un inteligente uso de su marca enmascarada bajo la marca McDowell's a lo largo de 
toda la película. Numerosas escenas se desarrollan en el pequeño restaurante de comida rápida de los McDowell's, y la manifiesta rivalidad con McDonald's permite que el propietario, Cleo McDowell's, aluda a ella en diferentes escenas y contextos.

Asimismo, otros géneros de entretenimiento como los videojuegos, que en ocasiones también presentan mundos irreales o fantásticos en los que puede resultar difícil emplazar marcas reales, han sido poblados en los últimos años con este tipo de marcas. La marca Sprunk que aparece en el videojuego Grand Theft Auto: San Andreas (Rockstar, 2004), guarda un parecido tan grande con la marca Sprite (tanto en la tipografía como en los colores utilizados) y su ubicación en el videojuego resulta tan elaborada que se ha afirmado que "parece haber sido desarrollada por un equipo de profesionales de una agencia de publicidad" (Vedrashko, 2006: 55). La marca aparece publicitada en grandes carteles de publicidad exterior en diversos escenarios del videojuego, en máquinas expendedoras repartidas por toda la ciudad, en los vasos de la comida que puede encargar el protagonista, en las estanterías de los supermercados, en cuñas radiofónicas, etcétera.

\section{Emplazamiento de producto inverso}

Un segundo formato detectado es el denominado emplazamiento de producto inverso (reverse product placement), que ha sido definido como "la creación de marcas ficticias en entornos ficticios que posteriormente se comercializan en el mundo real" (Gutnik et al., 2007: 18). Un conocido ejemplo de producto inverso son los caramelos Bertie Bott's Every Flavor Beans, surgidos de la imaginación de la autora de Harry Potter, J. K. Rowling, y comercializados por la marca Cap Candy (perteneciente a Hasbro). Nestlé también hace años que comercializa las barras de chocolate que producía Willy Wonka en la fábrica de chocolate imaginada por Ronald Dahl.

Entre los principales objetivos que pueden perseguir las organizaciones mediante el uso del emplazamiento de producto inverso destaca, en primer lugar, la reducción de costes a la hora de desarrollar el producto (Edery, 2006; Gutnik et al., 2007). En este sentido se ha afirmado que "puesto que es mucho menos caro lanzar un producto ficticio que manufacturar un producto real, el emplazamiento de producto inverso podría ser utilizado algún día para atraer el interés del público hacia un nuevo producto propuesto. Las empresas podrían 
lanzar productos online con el objetivo de crear el producto real en relación con la reacción del público al producto online" (Gutnik et al., 2007: 19). Con esta intención American Apparel introdujo una nueva línea de vaqueros en el mundo virtual Second Life dando a los usuarios la posibilidad de que pudieran vestir a sus avatares (representaciones virtuales de los usuarios) con su marca de ropa. El propósito era generar comentarios acerca de este nuevo producto antes de su lanzamiento al mercado. Además, al comprar ropa virtual para sus avatares en Second Life los consumidores obtenían un cupón de 15 por ciento de descuento para usar en las tiendas offline, con lo que se fijaron unos objetivos de promoción de ventas que también deja entrever futuras posibilidades para la comercialización de productos y servicios mediante esta clase de estrategias.

En segundo lugar, el emplazamiento de este tipo de productos en contenidos de ficción a los que los consumidores estén expuestos frecuente y regularmente puede facilitar objetivos como la notoriedad, el recuerdo y el reconocimiento de la marca. En el marco de la ficción audiovisual, por ejemplo, resulta evidente que "marcas" como Duff (marca de la cerveza favorita de Homero Simpson en la serie de animación Los Simpson) ya están posicionadas en la mente de un gran número de consumidores (los millones de telespectadores que siguen la serie) antes de ser lanzadas al mercado.Además, se ha detectado que el apego parasocial ${ }^{8}$ hacia los protagonistas de las series de ficción puede afectar positivamente a las actitudes de los consumidores hacia estas marcas. El apego parasocial juega un papel destacado en la influencia que ejercen los personajes mediáticos sobre las audiencias, ya que se ha detectado que las influencias referenciales ocurren a través de interacciones parasociales ${ }^{9}$ (Russell, Norman y Heckler, 2004). En el medio televisivo, Russell y Stern (2006) encontraron que el apego parasocial de un espectador al personaje que se relaciona con la marca de forma positiva en un programa de televisión actuó como moderador de las actitudes del espectador hacia el producto emplazado. Es decir, a mayor apego parasocial personaje/espectador, se descubrió una mayor actitud positiva del

${ }^{8} \mathrm{El}$ apego parasocial ha sido definido como "el grado en el que un personaje es visto como un referente lleno de sentido para otro" (Russell y Stern, 2006: 19).

${ }^{9}$ Las interacciones parasociales son aquellas acciones derivadas del desarrollo del apego parasocial entre un espectador y un personaje mediático. 
El emplazamiento de producto:

conceptualización, nuevos formatos

y efectos sobre el consumidor

espectador hacia el producto (si la relación producto/personaje es positiva), por lo que el emplazamiento de producto inverso también podría lograr diferentes objetivos afectivos.

En tercer lugar, mediante el emplazamiento de producto inverso se puede alcanzar un elevado grado de compromiso del consumidor con la marca emplazada. Se sabe que los consumidores pueden fantasear con productos ficticios o virtuales aparecidos en los medios y esto puede provocar comportamientos en los sujetos que van más allá de sus roles de consumidor (Molesworth, 2006; Molesworth y Jenkins, 2002). De tal suerte, los fans de ciertas series, películas o videojuegos pueden fantasear con la adquisición "real" de productos o servicios que son consumidos en la ficción por sus personajes favoritos. Por ejemplo, un grupo de fans de la película Regreso al futuro II (Zemeckis, 1985) orquestó una acción en Internet (denominada Operación McFly) para recoger firmas solicitándole a Nike que produjera las futuristas zapatillas que lucía Marty McFly (Michael J. Fox) en la película. Este hecho está directamente vinculado con el consumo simbólico (Belk, 1988; McCracken, 1986; Holbrook y Hirschmann, 1982) y puede desencadenar incluso rituales de consumo relacionados con las imágenes y productos ofrecidos por los medios.

Hay que reseñar que, además, el emplazamiento de producto inverso ejemplifica el análisis que se ha realizado desde las teorías postmodernas de la nueva naturaleza de los productos y servicios en los mercados actuales (Firat,Venkatesh, y Sherry, 1993; Firat y Shultz, 1997), ya que

...si el marketing moderno cree en los productos (y utiliza el discurso publicitario, por ejemplo, para transmitir la imagen de ellos que mejor refleje su valor práctico y funcional), la era postmoderna crea hiperrealidades (simulaciones) que son imágenes virtuales, o virtualizaciones, para las que se crean los productos. Es decir, es el producto el que se desarrolla para satisfacer la imagen que se ha creado de él y no a la inversa [Martí y Muñoz, 2008: 139].

\section{Marcas mejoradas}

Por último, la praxis del mercado manifiesta otro formato de emplazamiento: las marcas mejoradas, las cuales son emplazamientos de marcas o productos reales cuyas características y propiedades han sido modificadas y mejoradas virtualmente con el objetivo de que el espectador se las atribuya a la marca o producto “real”. Por ejemplo, la marca de automóviles Dodge diseñó un vehículo 
futurista volador, el Fantasticar, que fue emplazado en la película Los cuatro fantásticos y Silver surfer (Story, 2007). A pesar de que se haya cuestionado si el hecho de "tener el logo de la compañía o el nombre de la marca en un coche volador venderá coches reales a consumidores interesados en el valor, la calidad y el estilo" (Rotfeld, 2007: | 3 I), no se debe menospreciar el efecto de este tipo de acciones en otros resultados de las comunicaciones de marketing (como la construcción de marca), independientemente de los modelos reales que sea capaz de vender el emplazamiento. Es factible pensar que mediante la simulación de la fabricación de un vehículo de estas características se busque generar una transferencia implícita de valores y significados que haga posible que el espectador asocie a la marca Dodge atributos deseables para una marca de coches como son la innovación, la alta tecnología, el diseño o la vanguardia. Además, el emplazamiento permitió a Dodge utilizar el prototipo para una campaña de spots televisivos en los que se primaba la aparición del vehículo en la película, alertando a los espectadores de su presencia en ella y vinculando la imagen de Dodge a una franquicia (la de los Cuatro fantásticos) entre cuyos fans se pueden encontrar muchos de sus clientes potenciales.

El uso de estas marcas mejoradas es habitual en las películas del género de ciencia ficción, cuyos emplazamientos son utilizados por las marcas para mostrar propuestas y prototipos futuristas de sus productos, como el caso de Nokia, que emplazó un modelo futurista de videocomunicador de sobremesa en la película Minority Report (Spielberg, 2002). Bulgari fue otra de las marcas que también emplazó un innovador reloj holográfico de pulsera en la misma cinta.Audi dio un paso más allá en Yo, robot (Proyas, 2004) desarrollando específicamente un prototipo, el Audi RSQ, para ser emplazado en la película.

La aparición de estas marcas mejoradas apela a los juicios que realizan los consumidores sobre la información que se les presenta a través de los emplazamientos. Por ejemplo, se sabe que los espectadores podrían atribuir mentalmente beneficios o usos no mostrados en el emplazamiento (Alba y Hutchinson, 1987). De igual forma se puede especular que estos juicios acerca de la marca mejorada (innovación tecnológica, alto rendimiento, etc.) podrían transferirse a los productos reales de la marca. Como se ha sugerido, con niveles muy altos de procesamiento los consumidores podrían incluso exagerar la información que el emplazamiento presenta de la marca (Balasubramanian, Karrh y Patwardhan, 2006) con interpretaciones idiosincrásicas de cómo la marca satisface sus propias necesidades de identidad y expresivas (Maclnnis y Jaworski, 1989). 
El emplazamiento de producto:

conceptualización, nuevos formatos

y efectos sobre el consumidor

\section{Efectos del emplazamiento de producto en los consumidores}

Es evidente que si las organizaciones están experimentando con nuevos formatos de emplazamiento es porque intuyen que éstos pueden reportar diferentes beneficios al alcanzar distintos objetivos de marketing. En el marco del emplazamiento de producto, Balasubramanian, Karrh y Patwardhan (2006) proponen un marco conceptual basado en el modelo tradicional de jerarquía de efectos (Lavidge y Steiner, 196I). Esta propuesta asume una serie de antecedentes (personales y de diseño) que influyen en el procesamiento de la información (tanto sobre la memoria explícita como sobre la memoria implícita) y desencadenan en el consumidor una serie de efectos de carácter cognitivo, afectivo y comportamental.

\section{Resultados cognitivos}

Los dos principales resultados cognitivos que se espera obtener mediante el emplazamiento de producto son incrementos en el recuerdo de la marca y la mejora de las percepciones sobre ella (Babin y Carder, 1996; Balasubramanian, Karrh y Patwardhan, 2006; Johnstone y Dodd, 2000; Sabherwal, Pokrywczynski y Griffin, 1994).

El recuerdo de marcas emplazadas está determinado por la profundidad del procesamiento (memoria explícita/memoria implícita) que, a su vez, viene condicionado por el nivel de conciencia (alto/bajo) con el que se ha procesado el emplazamiento. Diversos estudios muestran cómo los emplazamientos producen efectos sobre la memoria explícita a corto plazo tal y como se detecta al medir el reconocimiento, la notoriedad o el recuerdo de marca (Babin y Carder, 1996; Baker y Crawford, 1995; Gupta y Lord, 1998; Johnstone y Dodd, 2000; Karrh, 1994; Nelson, 2002; Sabherwal, Pokrywczynski y Griffin, 1994). Cuando el emplazamiento de marca opera de una forma menos consciente, según Krugman (1965) sugiere que funcionan los anuncios de baja implicación, estas medidas sobre el recuerdo son inapropiadas, debiendo ser sustituidas por otras capaces de captar la memoria implícita.

Tanto las marcas enmascaradas, como el emplazamiento de producto inverso y las marcas mejoradas, pueden generar resultados sobre el recuerdo. Incluso se podría especular que las diferentes características de estos nuevos formatos conducirían a procesos de mayor elaboración cognitiva que los emplazamientos tradicionales, por lo que cabría esperar mejores resultados sobre 
la memoria (Petty, Cacioppo y Schumann, 1983). Por ejemplo, la decodificación, por parte del consumidor, de la información presentada por una marca enmascarada y su intento por incorporar esta información a los esquemas previos del consumidor relacionados con la marca real a la que representa, requeriría un mayor esfuerzo cognitivo que el procesamiento de un emplazamiento tradicional,y quizá mejores resultados sobre el recuerdo, efectos que han encontrado soporte empírico en contextos afines como la publicidad tradicional o el patrocinio (Cornwell,Weeks y Roy, 2005; Speed y Thompson, 2000).

Respecto al segundo efecto esperado, se sabe que las opiniones acerca de las marcas emplazadas pueden verse afectadas por los emplazamientos ya que "incluso los procesamientos que comprenden niveles de conciencia relativamente bajos podrían influir los juicios de los consumidores acerca de la tipicalidad ${ }^{10}$ de marca como, por ejemplo, la cuota de mercado percibida" (Balasubramanian, Karrh y Patwardhan, 2006: I3I). Un solo emplazamiento podría servir como referencia que modele las percepciones de la presencia de la marca en el mercado. En el caso de las marcas mejoradas, cabría preguntarse si el emplazamiento de un producto mejorado tecnológicamente de manera virtual es capaz de repercutir en la percepción sobre el desarrollo tecnológico de los productos reales fabricados por la marca.

Resultados afectivos

Entre los resultados afectivos derivados del procesamiento de un emplazamiento se encuentran: a) la valoración de la imagen de la marca, b) la identificación con la marca y c) las actitudes hacia la marca (Avery y Ferraro, 2000; Balasubramanian, Karrh y Patwardhan, 2006; Ferraro y Avery, 2000; Russell, I 998; Russell y Stern, 2006).

Dos estudios (Avery y Ferraro, 2000; Ferraro y Avery, 2000) han desarrollado una escala para medir el grado en el que una marca es valorada positivamente a través de un emplazamiento, lo que permitiría utilizar esta valoración de la imagen de la marca como variable dependiente en un análisis de regresión con diferentes variables de ejecución como variables independientes, de modo

${ }^{10}$ La tipicalidad o tipicidad de marca ha sido definida como la percepción del grado de representatividad de una marca en una categoría de producto determinada (Loken y Ward, 1990). 
que se pudiera determinar qué elementos de ejecución contribuyen en mayor medida a mejorar la imagen de marca.

La identificación con la marca trata de medir el grado de empatía generado por el emplazamiento. Según Balasubramanian, Karrh y Patwardhan (2006), la empatía y los procesos de identificación emocional son comunes a casi todos los emplazamientos, incluso aquellos procesados en un nivel bajo de conciencia. Russell (1998:359) llega a afirmar que esta empatía es "el ingrediente principal de la eficacia del emplazamiento de producto". Por otra parte, Hirschmann y Thompson (1997:53) han caracterizado la identificación como un medio por el que los consumidores negocian "sus percepciones de sí mismos y los objetivos personales en relación con las imágenes idealizadas presentadas por los medios de masas". En el momento en que la identificación con la marca es modelada por actores/personajes en los contextos de los emplazamientos, esta identificación puede ser aprendida. Es decir, en consonancia con la teoría del aprendizaje social de Bandura (1977), los individuos adquieren nuevas tendencias de respuesta mediante los comportamientos imitativos y los modelos. Russell y Stern (2006) han encontrado que el apego parasocial de un espectador al personaje que se relaciona con la marca de forma positiva en un programa actúa como moderador de las actitudes del espectador hacia el producto emplazado. Además, las audiencias pueden responder a los personajes de los medios con el deseo de comportarse como ellos (Hoffner y Cabtor, 1991). En el caso del emplazamiento de producto inverso, los consumidores podrían sentir un deseo de consumo incluso de marcas o productos ficticios que podría ser aprovechado por las organizaciones. Estos aspectos tienen que ver con el consumo simbólico (Belk, 1988; McCracken, I 986; Holbrook y Hirschmann, 1982) y pueden provocar comportamientos del consumidor en los que "se use una determinada marca en una situación determinada para adoptar una identidad social deseada" (Balasubramanian, Karrh y Patwardhan, 2006: 130). En este sentido, se sabe que las personas pueden dar a los demás la imagen deseada mediante un principio de asociación (Schlenker, 1980) vinculándose a imágenes y símbolos utilizados por el agente de referencia (por ejemplo, las gafas de sol utilizadas por un personaje cinematográfico). De acuerdo con Balasubramanian, Karrh y Patwardhan (2006: I32), es más probable obtener este resultado "cuando el espectador procesa la información de la marca de forma consciente y produce una elaboración acerca de la utilidad de la marca en la representación de sí mismo". 
Por último, los resultados empíricos en relación con los efectos de los emplazamientos respecto a las actitudes hacia la marca son contradictorios. Así, Karrh (1994) no detectó ningún cambio en la evaluación de marcas emplazadas, mientras que Russell (2002) sí percibió una mejora de la actitud hacia la marca. Balasubramanian, Karrh y Patwardhan (2006: I 32) sugieren que "niveles bajos/moderados de procesamiento consciente podrían producir el mayor impacto de un emplazamiento en las actitudes hacia la marca".

Resultados comportamentales

Los efectos del emplazamiento de producto de naturaleza comportamental pueden incluir: a) la intención de compra, b) la elección de marca y c) el comportamiento de uso de la marca (Baker y Crawford, 1995; Nedungadi, 1990; Morton y Friedman, 2002; Shapiro, Maclnnis y Heckler, 1997).

En primer lugar, pocos estudios han encontrado un efecto significativo de la exposición al emplazamiento sobre la intención de compra. Entre ellos, un estudio efectuado por Baker y Crawford (1995) que detectó que los sujetos expuestos a un emplazamiento manifestaron una intención de compra 16 por ciento superior a la manifestada antes de la exposición.

En cuanto a la elección de marca, la simple exposición, incluso sin memoria explícita sobre la misma, puede aumentar la probabilidad de que la marca sea incluida en el grupo de consideración (Shapiro, Maclnnis y Heckler, 1997). Nedungadi (1990) descubrió que la probabilidad de escoger una determinada marca puede incrementarse tras una exposición reciente a ella, incluso aunque los efectos afectivos como la preferencia de marca no se hayan modificado.

Finalmente, Morton y Friedman (2002) hallaron que los emplazamientos en películas (especialmente aquellas vinculadas a la imagen del producto emplazado en la película) afectaban al comportamiento de uso del producto. También Pervan y Martin (2002) han sugerido que los anunciantes deberían estudiar la imaginería de consumo asociada a los productos que aparecen emplazados (en este caso en series de televisión) puesto que puede aporta información significativa de cómo éstos son consumidos.

\section{Conclusiones, implicaciones y futuras líneas de investigación}

El incremento del emplazamiento de producto como herramienta de las comunicaciones de marketing está provocando que las organizaciones experimenten 
con formas novedosas de realizar este tipo de emplazamiento en nuevos contextos y con diferentes objetivos. El presente trabajo constituye una revisión conceptual en torno a tres variantes del emplazamiento de producto que están ganando peso en la praxis empresarial en cuanto instrumentos de gestión de la comunicación de marca: las marcas enmascaradas, el emplazamiento de producto inverso y las marcas mejoradas.

En primera instancia, por medio de las marcas enmascaradas, las organizaciones podrían emplazar sus marcas de forma congruente en contextos en los que no sería posible emplazar marcas reales, por ejemplo en mundos fantásticos. No obstante, estas marcas enmascaradas permitirían a los consumidores realizar asociaciones inmediatas con las marcas reales a las que representan, hecho que podría beneficiar los efectos derivados del procesamiento de la información presentada por estas marcas enmascaradas a las marcas reales.

Por otra parte, mediante el emplazamiento de producto inverso, las organizaciones podrían explotar comercialmente marcas que ya se encontraran bien posicionadas en las mentes de los consumidores debido a un consumo simbólico previo efectuado por ellos a través de su adquisición de contenidos de entretenimiento facilitados por los medios de comunicaciones de masas.

Finalmente, las marcas mejoradas permitirían a las organizaciones emplazar virtualizaciones idealizadas de sus marcas, capaces de representar implícitamente las aspiraciones de la marca. Mediante el emplazamiento de marcas o productos mejorados se podrían conseguir atribuciones de valor (como innovación o diseño) por parte de los consumidores expuestos a tales emplazamientos.

Al ampliar considerablemente el área de actuación y los objetivos del emplazamiento de producto tradicional, estos nuevos formatos abrirían distintas posibilidades de acercamiento de las marcas a los consumidores a través de emplazamientos dotados de nuevos valores. Por ejemplo, las marcas enmascaradas podrían cargarse de significados irónicos que requerirían un mayor esfuerzo de decodificación del mensaje por parte de los espectadores; como consecuencia, un mayor procesamiento central del emplazamiento podría beneficiar los efectos cognitivos (por ejemplo, recuerdo y reconocimiento) de tal emplazamiento (Petty, Cacioppo y Schumann, 1983). Por otro lado, las virtualizaciones idealizadas presentadas por las marcas mejoradas podrían afectar directamente a las interpretaciones y opiniones acerca de estas marcas; estas 
atribuciones implícitas de determinadas características potenciadas por las marcas mejoradas podrían incluso modificar positivamente las percepciones y actitudes sobre estas marcas (Maclnnis y Jaworski, 1989; Alba y Hutchinson, 1987).

La colonización de otros espacios audiovisuales (como las películas de animación dirigidas al público infantil) por nuevos formatos de emplazamiento como las marcas enmascaradas plantea temas de debate en torno a aspectos éticos, morales y legales de tales formatos. No hay que olvidar que las audiencias infantiles (sobre todo los menores de I 3 años) cuentan con un estatus especial en el marco de la publicidad y otras comunicaciones de marketing debido a su limitada capacidad para identificar y analizar críticamente la naturaleza persuasiva de este tipo de comunicaciones.Asimismo, el hecho de que las organizaciones puedan utilizar estos espacios para alcanzar a audiencias adultas que también son expuestas a estos mensajes podría derivar en una exposición de las audiencias infantiles a determinados productos (bebidas alcohólicas, por ejemplo) no aptos para esas edades. Estos nuevos formatos quizá evidencien la necesidad de dotar a esta clase de comunicaciones de un marco regulador largamente exigido por las asociaciones de consumidores.

Desde un punto de vista académico, estos nuevos formatos también plantean nuevas cuestiones de investigación acerca de los efectos de estos emplazamientos. En el caso del uso de marcas enmascaradas, resulta crucial conocer si este tipo de emplazamientos es capaz de generar asociaciones inmediatas entre las marcas enmascaradas y las marcas reales a las que representan; también es necesario conocer en qué medida se produce una transferencia entre los juicios efectuados sobre las marcas enmascaradas hacia las reales; o cómo son percibidas estas marcas enmascaradas por los consumidores. En cuanto al emplazamiento de los productos inversos, se desconoce por completo cómo son percibidos estos por los consumidores (tanto en relación con sus propios valores percibidos como a los juicios comparativos elaborados en relación a otros productos de la misma categoría de producto ya existentes en el mercado) y cómo afecta la implicación con la categoría de producto a las actitudes y preferencias hacia estos productos inversos. Finalmente, las marcas mejoradas plantean cuestiones como el efecto de los juicios de los consumidores sobre estas marcas en el valor o la imagen de las marcas reales a las que representan. 
El emplazamiento de producto:

conceptualización, nuevos formatos

y efectos sobre el consumidor

FUENTES CONSULTADAS

Alba, J.W. y J.W. Hutchinson (1987). "Dimensions of Consumer Expertise”. Journal of Consumer Research, 13, 4 I I-454.

Avery, R.J.y R. Ferraro (2000).“Verismilitude or Advertising? Brand Appearances on Prime-Time Television". The Journal of Consumer Affairs, 34 (2), 217-244.

Babin, L.A.y S.H. Carder (1996). "Viewers' Recognition of Brands Placed within a Film”. International Journal of Advertising, I5 (2), I40-I5I.

Baker, M.J. y H.A. Crawford (1995). Product Placement. Working Paper 95 (2). Glasgow: Departamento de Marketing, Universidad de Strathclyde.

Balasubramanian, S.K.( 1994)."Beyond Advertising and Publicity:Hybrid Messages and Public Policy Issues”. Journal of Advertising, 23 (4), 29-46.

Balasubramanian, S.K., J.A. Karrh y H. Patwardhan (2006). “Audience Response to Product Placements: An Integrative Framework and Future Research Agenda". Journal of Advertising, 35 (3), I I5- I4I.

Bandura,A. (1977). Social Learning Theory. Chicago:Aldine-Atherton.

Belk, R.W. (1988). "Possessions and the Extended Self". Journal of Consumer Research, I5, I39-168.

Consoli, J. (2004). “Running in Place(ment)”. Brandweek, 45 (28), 4-6.

Cornwell,T.B., C.Weeks y D. Roy (2005). “Sponsorship-linked Marketing: Opening the Blackbox". Journal of Advertising, 34 (2), 23-45.

Edery, D. (2006). "Reverse Product Placement in Virtual Worlds". Harvard Business Review, 84 (I2), 24.

Elliot, S. (1992). "Product Placement Is Under New Attack”. New YorkTimes, 24 de septiembre de 1992, 4.

Ferraro, R. y R.J.Avery (2000). “Brand Appearances on Prime-time Television”. Journal of Current Issues and Research in Advertising, 22, I- I5.

Fill, C. (2006). Marketing Communications. Londres: Prentice-Hall.

Firat, A.F. y C.J. Shultz (1997). "From Segmentation to Fragmentation Markets and Marketing Strategy in the Postmodern Era”. European Journal of Marketing, 3I (3-4), I 83-200.

Firat, A.F., A.Venkatesh y J.F. Sherry, Jr. (eds.) (1993). International Journal of Research in Marketing, número especial, 10 (3), Postmodernism, Marketing and the Consumer. 
Galician, M.L. y P.G. Bourdeau (2004). "The Evolution of Product Placements in Hollywood Cinema: Embedding High-Involvement 'Heroic' Brand Images". Journal of Promotion Management, I0 (I/2), I5-36.

Gupta, P.B. y K.R. Lord (1998). "Product Placement in Movies. The Effect of Prominence and Mode on Audience Recall”. Journal of Current Issues and Research in Advertising, 20 (I), 47-59.

Gutnik, L., et al. (2007). New trends in product placement [en línea]. Disponible en:http://www.ischool.berkeley.edu/ hal/Courses/StratTech07/Tech/ Preso/D-placement.doc [2007, 7 de julio].

Hirschmann, E.C.y C.J.Thompson ( 1997)."Why Media Matter:Toward a Richer Understanding of Consumers' Relationships with Advertising and Mass Media”. Journal of Advertising, 26 (I), 43-60.

Hoffner, C.y J. Cabtor (199I)."Perceiving and Responding to Mass Media Characters", en J. Bryant y D. Zillmann (eds.). Responding to the Screen. Hillsdale: Lawrence Erlbaum, 63-I0I.

Holbrook, M.B.y E.C. Hirschmann (1982). “The Experientials Aspects of Consumption: Consumer Fantasies, Feelings, and Fun”.Journal of Consumer Research, 9, I32-140.

IMDB (20I0). All-Time Worldwide Box Office [en línea]. The Internet Movie Database. Disponible en: http://www.imdb.com/boxoffice/ alltimegross?region=world-wide [2010, 2 de marzo].

Johnstone, E.y C.A. Dodd (2000). "Placements as Mediators of Brand Salience within a UK Cinema Audience". Journal of Marketing Communications, $6(3),|4|-158$.

Karrh, J.A. (1994). "Effects of Brand Placements in Feature Films", en K.W. King (ed.). Proceedings of the Conference of the American Academy of Advertising. Athens:American Academy of Advertising, 90-96. (1998). "Brand Placement: A Review”. Journal of Current Issues and Research in Advertising, 20 (2), 3 I -49.

Krugman, H.E. ( 1965). "The Impact of Television Advertising: Learning without Involvement". Public Opinion Quaterly, 29, 349-356.

Lavidge, R.J. y G.A. Steiner (196I). "A Model for Predictive Measurements of Advertising Effectiveness". Journal of Marketing, 24, 59-62.

Lavin, M. (1995). “Creating Consumers in the 1930's: Irna Phillips and the Radio Soap Opera”. Journal of Consumer Research, 22, 75-89. 
Loken, B. y J. Ward (1990). "Alternative Approaches to Understanding the Determinants of Typicality". Journal of Consumer Research, 17 (2), septiembre, III-I 26.

López-Pumarejo,A. ( 1987). Aproximación a la telenovela. Madrid: Cátedra.

Maclnnis, D.J.y B.J.Jaworski ( 1989)."Information Processing from Advertisements: Toward and Integrative Framework”. Journal of Marketing, 53, I-23.

Martí,J. (2010). Marketing y publicidad en videojuegos: product placement, in-game advertising y advergaming. Madrid: ESIC.

Martí,J.y P. Muñoz (2008). Engagement Marketing: Una nueva publicidad para un marketing de compromiso. Madrid: Financial Times/Prentice Hall.

McCracken, G. (1986). "Culture and Consumption:A Theoretical Account of the Structure and Movement of the Cultural Meaning of Consumer Goods". Journal of Consumer Research, I3 (I), 7I-84.

Meenaghan,T.(I99|)."Sponsorship - Legitimising the Medium”. European Journal of Marketing, 25, 5- I0.

Molesworth, M. (2006). "Real Brands in ImaginaryWorlds: Investigating Players' Experiences of Brand Placement in Digital Games".Journal of Consumer Behaviour, 5 (4), 355-366.

Molesworth, M. y K. Jenkins (2002). "Young Adults' Uses of Commercial and Non- Commercial Internet Content", en Proceedings of the Academy of Marketing Conference. Nottingham:Academy of Marketing Conference. Morton, C.R. y M. Friedman (2002). "I Saw it in the Movies: Exploring the Link between Product Placement Beliefs and Reported Usage Behavior". Journal of Current Issues and Research in Advertising, 24 (2), 33-40.

Nebenzahl, I.D. y E. Secunda (1993). “Consumers' Attitudes toward Product Placement in Movies". International Journal of Advertising, I 2, I - I I.

Nedungadi, P. (1990). "Recall and Consumer Consideration Sets: Influencing Choice without Altering Brand Evaluations". Journal of Consumer Research, 17, 263-276.

Nelson, M.R. (2002). "Recall of Brand Placements in Computer/Video Games”. Journal of Advertising Research, 42 (2), 80-92.

Panda,T.K. (2004). "Effectiveness of Product Placements in Indian Films and its Effects on Brand Memory and Attitude with Special Reference to Hindi Films". The ICFAI Journal of Marketing Management, agosto, 42-56. 
Pervan, S.J.y B.A.S. Martin (2002)."Product Placement in US and New Zealand Television Soap Operas:An Exploratory Study”.Journal of Marketing Communications, 8 (2), I0I-II3.

Petty, R., J. Cacioppo y D. Schumann (I983). "Central and Peripheral Routes to Advertising Effectiveness:The Moderating Role of Involvement". Journal of Consumer Research, 10 (2), I 35- I 45.

PQ Media, (2008). Alternative Media Forecast: 2008-20I2 [en línea]. Disponible en: http://www.pqmedia.com/about-press-20080326-amf2008.html [2008, 10 de octubre].

Real Academia Española (200I). Diccionario de la Lengua Española. Madrid: Espasa Calpe.

Rotfeld, H.J. (2007). “Misplaced Marketing; Is There a Strategy Behind Buying Advertising Time and Space? Journal of Consumer Marketing, 24 (3), I3I-I32.

Russell, C.A. (1998). "Toward a Framework of Product Placement:Theoretical Propositions", en J.W.Alba y J.W. Hutchinson (eds.). Advances in Consumer Research, 25, Provo: UT, Association for Consumer Research, 357-362.

(1999). Popular Culture and Persuasion:An Investigation on Product Placements' Effectiveness. Tesis doctoral, Universidad de Arizona.

(2002). "Investigating the Effectiveness of Product Placements in Television Shows: The Role of Modality and Plot Connection Congruence on Brand Memory and Attitude". Journal of Consumer Research, 29 (3), 306-318.

Russell, C.A. y B.B. Stern (2006). "Consumers, Characters, and Products: A Balance Model of Sitcom Product Placement Effects". Journal of Advertising, 35 (I), 7-2I.

Russell, C.A.,A.T. Norman y S.E. Heckler (2004). "People and 'their' Television Shows:An Overview of Television Connectedness”, en L.J.Shrum (ed.). The Psychology of Entertainment Media. Mahwah: Lawrence Erlbaum, 275-290.

Sabherwal, S., J. Pokrywczynski y R. Griffin (1994). "Brand Recall for Product Placements in Motion Pictures: A Memory-Based Perspective", en Proceedings Conference of the Association for Education in Journalism and Mass Communication, Atlanta, GA. 
El emplazamiento de producto:

conceptualización, nuevos formatos

y efectos sobre el consumidor

Schlenker, B. (1980). Impression Management. Belmont: Brooks/Cole.

Schultz, D.E. (1996). “The Inevitability of Integrated Communications”. Journal of Business Research, 37 (3), I39-146.

Shapiro, S., D.J. Maclnnis y S.E. Heckler (1997). "The Effects of Incidental Ad Exposure on the Formation of Consideration Sets". Journal of Consumer Research, 24, 94-104.

Speed, R. y P. Thompson (2000). “Determinants of Sports Sponsorship Response". Journal of the Academy of Marketing Science, 28 (2), 226-238.

Vedrashko, I. (2006). Advertising in Computer Games [en línea]. Tesis de master, Massachussets Institute of Technology. Disponible en: http:// gamesbrandsplay.com/files/vedrashko_advertising_in_games.pdf [2007, 18 de junio].

Vranica, S. (2009). HSN Starts Mixing Ads into its Usual Sales Pitches [en línea].The Wall Street Journal, 28 de septiembre. Disponible en: http://online. wsj.com/article/ SBI25408792465344603.html [20 I0,6 de febrero]. 